stem cells, which are derived artificially from somatic cells.

Regulatory policies for SCNT in different states and countries must be in agreement, and should adhere to the ethical guidelines for oocyte procurement issued by the International Society for Stem Cell Research. This will help to ensure that SCNT research proceeds with the requisite oversight and fair recruitment and compensation practices for oocyte providers (see also Nature 442, 629-630; 2006).

Insoo Hyun, Paul Tesar Case Western Reserve University, Cleveland, Ohio, USA. insoo.hyun@case.edu Competing financial interests declared. See http://dx.doi. org/10.1038/478036c.

\section{Energy should form its own discipline}

The international energy system needs an overhaul. The sector is multidisciplinary: it must serve modern civilization without compromising economic opportunity, undermining national security or impinging on the environment. Yet innovation today prioritizes improvements to discrete technologies and progress in single disciplines rather than rebuilding the whole system. A more joined-up approach is needed, beginning with education.

Retooling the system will require a range of experts who understand new technologies and can translate them to the public, while considering the economic drivers necessary for their adoption.

In the United States, for example, the educational framework for undergraduates does not always keep pace with advances in science, engineering and innovation. Even though energy is a leading international priority, it lacks definition in universities, where it is largely perceived as a professional pursuit, or as a subset of fields such as petroleum engineering. Often, students are exposed only to glimpses of the sector and do not acquire an integrated, systems-level perspective.

Whereas institutions such as Duke University in Durham, North Carolina, the University of Texas at Austin and the University of British Columbia in Vancouver, Canada, have created programmes to address the changing energy landscape, none offers an interdisciplinary energy-focused degree at undergraduate and graduate levels.

We propose that large energy departments should be set up at universities worldwide to tie seemingly disparate fields of knowledge together. Graduates could move between disciplines to promote ideas and work towards practical solutions. By fostering an open dialogue between specialists, this nascent labour force would then be well equipped to navigate through all of the technical, political and social issues related to energy.

Sheril R. Kirshenbaum,

Michael E. Webber University of Texas at Austin, Texas, USA. sheril.kirshenbaum@mail.utexas. edu

\section{Giant dam threatens Brazilian rainforest}

Brazil's rainforest is under further threat from plans to build a giant hydroelectric dam on the Xingu River, a tributary of the Amazon River in Pará state. Plans for the dam, known as Belo Monte, have been approved by the environment agency. These come on top of pending changes to the Brazilian Forest Code that could allow deforestation of up to 20 million hectares of rainforest (Nature 476, 259-260; 2011).

The US\$17-billion dam, together with four planned upstream dams, will have a combined hydroelectric potential of 21,600 megawatts. Leaders of the Brazilian energy sector argue that the dams could help to preserve the Amazon. But their construction will flood vast areas of tropical rainforest, jeopardizing ecosystem functions and species survival, increasing greenhouse-gas emissions and displacing tens of thousands of forest peoples.

Brazil is a world leader in clean-energy production. However, the dams will release into the atmosphere enormous quantities of methane - a greenhouse gas that is 25 times more potent than carbon dioxide.

Much of the electricity generated by Belo Monte is likely to be used in the production of aluminium ingots for export (see go.nature.com/latlx3), making the environmental and social impact of the dam's construction even harder to justify.

Brazil must strive to control deforestation more effectively by strengthening its forest laws and consolidating the United Nations' REDD policy (for 'reduced emissions from deforestation and forest degradation'). Otherwise, the steady destruction of the country's tropical rainforest will have consequences well beyond its borders.

Alison G. Nazareno Federal University of Santa Catarina, Florianópolis, Brazil.

alison_nazareno@yahoo.com.br

Thomas E. Lovejoy Heinz

Center for Science, Economics and the Environment, Washington DC, USA.

\section{Pilot scheme for misconduct database}

Researchers, journal editors and scientific institutions should work together to improve communication about misconduct cases. Although published retractions are logged by PubMed and other databases, and by blogs such as Retraction Watch (http://retractionwatch. wordpress.com), the scientific community needs a way to identify flawed articles that have not been formally retracted but have been assessed as containing falsified data or having ethical problems (see, for example, Nature 476, 263-264; 2011).

To this end, we have piloted an open database of publications for which misconduct has been established by committees (such as offices of research integrity within research institutions). The database is collaborative and is coupled to an online platform on which scientific integrity can be openly and constructively debated (see www.scientificredcards.org and T. Flutre et al. Eur. Sci. Ed. 36, 51-52; 2010).

The website focuses on the publications and not the authors, to avoid 'naming and shaming'. It has been legally validated by the French National Commission on Informatics and Liberty, so that such information can be made public while respecting privacy laws.

To expand this initiative, the legal implications would have to be considered. It would need to be endorsed by the research community, which would cooperate to maintain and moderate it. Extensive publicity would be essential to ensure that the facility is used effectively.

Our pilot project offers a route to reinforcing society's trust in science. Creating a public library of misconduct through a collaborative web platform is a timely, transparent and efficient way for the research community to communicate about possible scientific impropriety.

Timothée Flutre University of Chicago, Illinois, USA. Thomas Julou Ecole Normale Supérieure, Paris, France. Livio Riboli-Sasco Paris Descartes University, France. Claire Ribrault Université Paris Diderot, France. contact@scientificredcards.org

\section{Discovery inspires those seeking tenure}

I strongly disagree with David Helfand's view that tenure is the "social filter" that selects for professors who are "most attracted to lifetime security" (Nature 477, 158-159; 2011).

For most young scientists attempting to scale the ladder of modern academia, I wager that the promise of scientific and intellectual discovery and the chance to inspire younger people are the real incentives.

Barbara-Ann Lewis

Northwestern University,

Evanston, Illinois, USA.

b-lewis@northwestern.edu 